\title{
Multichannel seismic image of the crustal thinning at the NE Iberian margin combining normal and wide angle reflection data
}

\author{
J. Gallart, N. Vidal and J.J. Dañobeitia \\ Institute of Earth Sciences-CSIC, Barcelona, Spain
}

\begin{abstract}
The seismic image of the Moho at the transition from the NE Iberian Peninsula to the Western Mediterranean Sea is investigated using coincident steep and wide-angle reflection data merged into a single stacked and migrated section. The multichannel analysis of onshore/offshore large-aperture data provides new insight on the deep structure in areas where the steep sections lack penetration, and reveals that the crust undergoes a strong but continuous thinning along the flanks of the Valencia trough. The combined seismic image indicates that almost half of the continental crust $(14-15 \mathrm{~km})$ is lost in less than $60 \mathrm{~km}$ horizontal distance.
\end{abstract}

\section{Introduction}

Deep vertical reflection seismic prospecting is regarded as the most powerful tool to investigate the fine structure of the crust. Near-vertical reflection surveys of the whole crust developed in the last 10-15 years have not replaced, however, wide-angle seismic profiling in its ability to constrain not only seismic velocities but also structural features of major boundaries like the Moho. In some areas, such as continental margins associated with strong lateral variations in crustal thickness and velocity distribution, the image of the Moho is even better resolved from dense-spaced wide-angle than from near-vertical measurements (Holbrook et al., 1992). A largeaperture geometry has the advantage of higher energy returns from post-critical Moho reflections and allows to "undershot" the uppermost crustal obstacles to the vertical penetration of energy (thick sedimentary covers, high impedance contrasts, etc.). In tectonic domains studied by coincident near-vertical and wide-angle reflection surveys, consistency of results about Moho is generally observed (see review in Mooney and Brocher, 1987). Discrepancies could be related to different interpretation approaches, developed from separated nearvertical and wide-angle data sets. The wide-angle Moho is easily identified by the distinctive character of the PmP onsets on the record-sections, whereas in near-vertical surveys the Moho is commonly associated with the deepest visible crustal reflections on the stacked sections.

We analyze here seismic reflection data from small and large offsets in an integrated manner. The image of the Moho at the transition from the NE Iberian Peninsula to the western Mediterranean is reconstructed from coincident multichannel steep and wide-angle data by processing and merging them into a single stacked and migrated seismic section.

Copyright 1995 by the American Geophysical Union.

Paper number 94GL03272

0094-8534/95/94GL-03272\$03.00
The NE Iberian Peninsula and the transition to the Mediterranean Sea have undergone complex tectonics since Cenozoic times. Within a general compressive regime between the European and African plates, and surrounded by Alpine ranges (Figure 1), the area was affected by Neogene extensional processes that gave way to the Valencia trough. Extensive geoscience research has been carried out in the area since the late eighties. Crustal thinning related with the Valencia trough extensional tectonics has been reported from several structural studies (see review in Banda and Santanach, 1992). The crustal reflectivity along strike in the lberian and Balearic continental margins has been illustrated in the Valsis experiment (Pascal et al., 1992; Torné et al., 1992; Collier et al., 1994), but a complete seismic picture of the lateral evolution of the deep crust across strike is still lacking. We present here new data of the Spanish ESCI reflection experiment, aimed at providing a crustal transect from the southern Pyrenean foreland to the south Balearic basin, across strike of structures. It integrates land and marine near-vertical and wide-angle data.

Near-vertical seismic section of the NE Iberian PeninsulaWestern Mediterranean transition

The near-vertical land and marine reflection profiles, which have a geographical continuity, are displayed in a composite

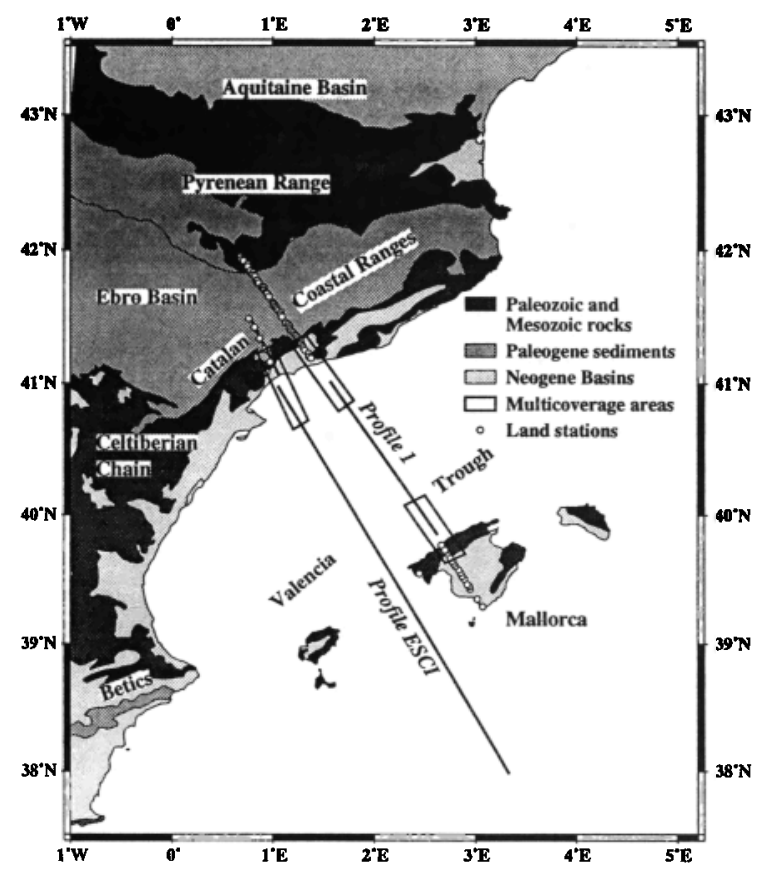

Figure 1. Frame of the Valencia trough and its margins, including the seismic reflection profiles, multicoverage wideangle areas and land stations considered. 
section in Fig. 2, and show significant differences in the reflectivity pattern. On the Iberian mainland, abundant reflections are present between 5.5 and $11 \mathrm{~s}$ TWT. The $12 \mathrm{~km}-$ wide, low-velocity Neogene Reus basin onshore attenuates the energy and causes a pull-down effect in the reflectivity (Gallart et al., 1994). Offshore, deep reflections are not imaged in the first $20 \mathrm{~km}$ of the profile. Where present, they lie at 7.5-8 s TWT and are attributed to the Moho, according to the lower crustal reflectivity recognizable in some places at the Catalan margin between 5 and $8 \mathrm{~s}$ TWT.

Apparently, this seismic picture may suggest an imbrication and shortening of two crusts of different thickness, in a similar way to that reported in the Pyrenees, between the Iberian and the European crusts at the North Pyrenean Fault level (Suriñach et al., 1993). This would have strong implications for geodynamical modelling of the area. However, as there is a gap of $20-30 \mathrm{~km}$ in the image of the deep reflectivity, the transition between the thick and thin crust is not well resolved with the near-vertical data. With the aim of filling up this gap, we have undertaken an analysis in terms of conventional reflection seismics of the dense wide-angle data available in the area, which involve different sampling paths and stronger reflected energies.

\section{Wide-angle data analysis}

The wide-angle data considered come from two parallel profiles $30 \mathrm{~km}$ apart (Fig. 1). First, the ESCI marine air-gun profile recorded on land by 6 stations at $10 \mathrm{~km}$ intervals. Second, the marine profile I from explosive sources (Dañobeitia et al., 1992) recorded by 50 stations in the Iberian mainland and 20 stations in Mallorca.

As a first approach, we performed velocity-depth modelling through classical forward analysis of arrival times and amplitudes. Clear $\mathrm{Pg}$ and $\mathrm{Pn}$ refracted phases, and intermediate (PiP) and Moho (PmP) reflections identified in the recordsections were used to derive models consistent with all the land stations. A significant crustal thinning is inferred (Figure 3), but models either with a continued rising of the Moho up to 14-15 km depth at the Valencia trough axis, or having more constant depths around $18 \mathrm{~km}$ across the trough are compatible with the data. Velocities in the uppermost mantle range between 7.8 and $8.0 \mathrm{~km} / \mathrm{s}$.

Gravity modellings performed along the two profiles (Gallart et al., 1994) are in agreement with seismic results, and provide additional constraints for a $50 \%$ thinning of the lower crust along the Catalan margin.

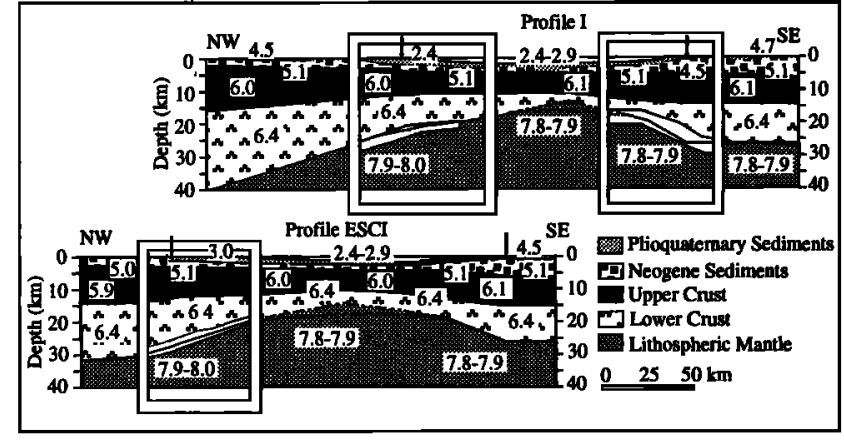

Figure 3. Best-fitting results of the forward modelling along profiles I and ESCI, after the data recorded on the land stations of Fig. 1. Numbers are velocities in $\mathrm{km} / \mathrm{s}$. The white boxes delineate the wide-angle multicoverage areas and show the consistency in the Moho location between the classical velocity-depth models and the migrated sections (see Fig. 5).

\section{Multichannel wide-angle processing}

The geometry of the reflection profiles and the piggy-back recordings on land indicate that wide-angle multiple coverage is achieved in some places (Fig. 1), concerning mainly the onshore/offshore transition. Therefore, we decided to undertake a multichannel processing of these data, similar to the conventional one for the steep reflection data. The analysis has been focused on the PmP Moho reflected phase, clearly observable on the sections for offsets ranging between $\mathbf{4 0}$ and $160 \mathrm{~km}$. An intermediate PiP reflection from the top of the lower crust is also correlated in the individual record-sections along distances of $20-30 \mathrm{~km}$, but multiple coverage for this is only achieved in a short area near the coast, due to the $10 \mathrm{~km}$ spacing between the recording stations.

In order to compare and merge the final steep and largeaperture stacked sections, the processing techniques applied to both data sets, using the ITA-Landmark software, have been kept as similar as possible. Hereafter, noteworthy aspects of the wide-angle multichannel processing will be emphasized.

a) Receiver-gathers and CMP sorting

Edition of traces, muting and band-pass filtering (3-20 Hz) were first applied to the large-aperture receiver-gathers. Due to the large offsets involved which vary by more than $100 \mathrm{~km}$, special care should be taken of the geometry and bin-width. On average, a fold of 30 is achieved in profile ESCI by considering bin-widths of $1000 \mathrm{~m}$, which is compatible with the velocities and wavelengths characteristic of these data. $A$

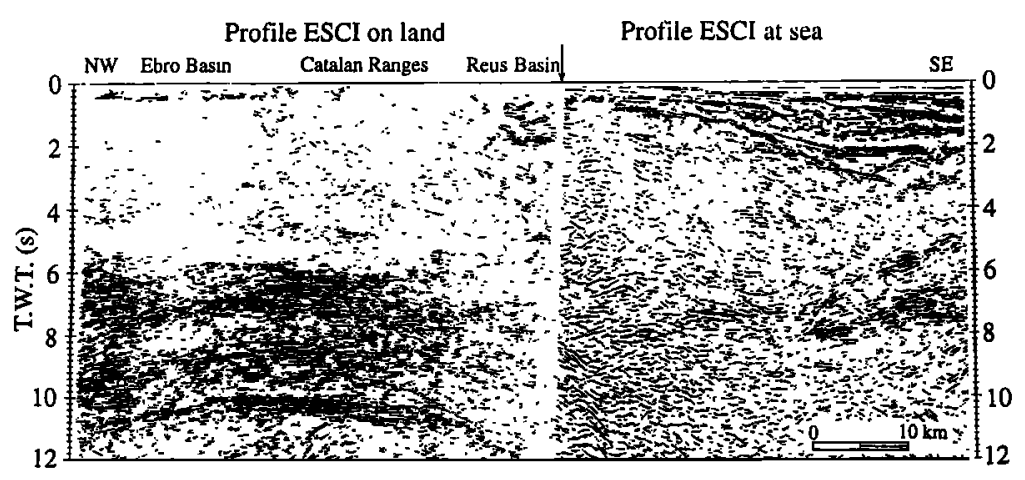

Figure 2. Composite stacked section (unmigrated) of the near-vertical ESCI profiles on land (left side) and at sea (right side). The arrow marks the shoreline. 


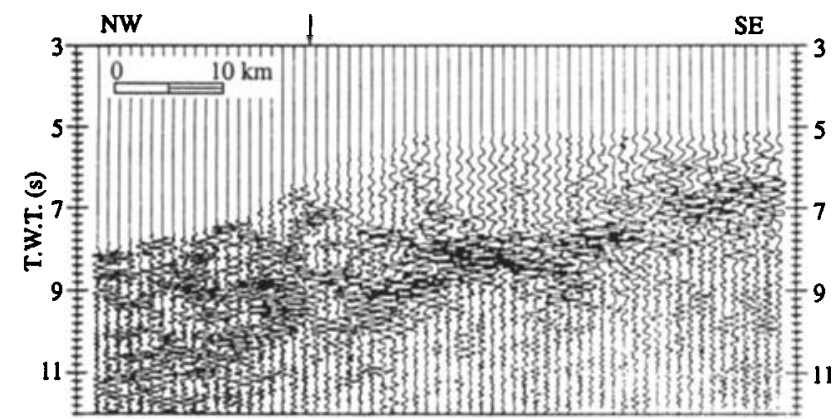

Figure 4. Stacked section after the multichannel wide-angle processing of profile ESCI. The arrow indicates the shoreline. CMP spacing is $1 \mathrm{~km}$.

single CMP gather is therefore build up with data coming from 3-4 different land stations.

Removing of refracted energy attempted with $f-k$ filtering could only be achieved with an important distortion of the reflected one, probably due to the similar wavenumbers and frequency content of our refracted and reflected phases. Therefore, we applied in the receiver-gathers a direct mute of refractions, considering that they are clearly identified and separated from the reflected phases of interest.

Ringing of the signal is attenuated by using predictive deconvolution with rather long operator lengths of 1 to $2 \mathrm{~s}$, and a predictive gap of $0.1 \mathrm{~s}$. Statics have also been considered, specially the topographic corrections to account for station elevations and water depth under shots. Residual statics algorithms are not well adapted for time shifts up to several tenths of a second, and do not improve significantly the stacked section.

b) Stacking and migration

Dynamic corrections (NMO: normal move-out) are most essential for wide-angle data. Due to the large offsets involved, the full NMO correction must be applied instead of two-terms approximations valid for small offset/depth ratios (Vidal et al.,
1994). NMO is very sensitive in this case to the velocities considered. These can be constrained to better than $0.1 \mathrm{~km} / \mathrm{s}$ by fitting data at largely different offsets. After the NMO correction, mute must be applied for some far-offset traces with important stretching.

The stacked section is shown in Fig. 4. Even though the CMP trace interval is $1 \mathrm{~km}$, Moho reflections are clearly imaged, and document a continuous crustal thinning, between $10.5 \mathrm{~s}$ TWT at $20 \mathrm{~km}$ onshore and $6 \mathrm{~s}$ TWT at $40 \mathrm{~km}$ offshore. Reflectivity from the lower crust is observed beneath the shoreline, but its lateral continuity cannot be controlled due to the large spacing of recording stations.

Best migrated sections are obtained for algorithms based on the time-shift method, using a laterally constant velocity deduced from the forward modelling. Modifications of up to $10 \%$ in the migration velocity result in the same reflectivity pattern but shifted depths. Migration algorithms based on finite differences and considering velocities varying laterally and at depth have also been tested, but the images are rather monocromathic, with some distortions and artifacts.

\section{A combined stacked section: discussion and conclusions}

A combined section by merging the steep and large-aperture data has been produced. Sampling rates were homogeneized first, and a decimation applied to the steep CMP data up to a common spacing of $1 \mathrm{~km}$. Lateral and vertical energy balancing was needed to compensate for energy differences related with the strong wide-angle reflections.

The combined stacked and migrated section (Fig. 5) shows a remarkable coherency between near-vertical and wide-angle data sets. This section maps for the first time the lateral evolution at depth across strike in the Valencia trough and its flanks, and reveals that the crust undergoes a strong but continuous thinning. In the transition seawards of the NE Iberian Peninsula, almost half of the crustal thickness (up to $14-15 \mathrm{~km}$ ) is lost in less than $60 \mathrm{~km}$ horizontal distance. The

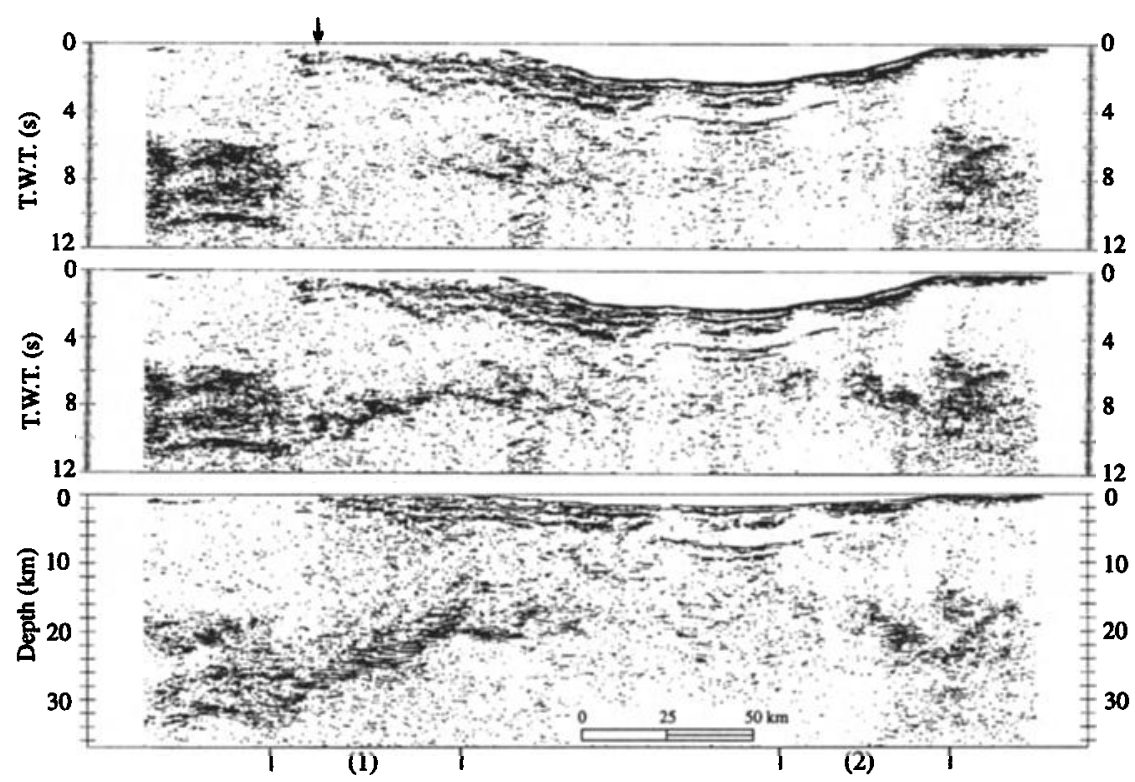

Figure 5. A $250 \mathrm{~km}$-long seismic crustal transect from the Ebro Basin (left), across the Valencia trough (middle), up to the Balearic Promontory (right). The upper panel shows the near-vertical stacked section, decimated to a common spacing of $1 \mathrm{~km}$. Middle and lower panels show the time- and depth-migrated sections after processing and merging the near-vertical and the wide-angle reflection data sets. (1): wide-angle data from profile ESCI; (2): wide-angle data projected broadside from profile I. 
crust remains of continental type according to the velocities deduced in the forward modelling.

At the conjugated (Balearic) flank of the Valencia trough a similar analysis has been performed, using the steep data of profile ESCI and the wide-angle data of the profile $1,30 \mathrm{~km}$ apart, under the assumption of lateral continuity of structures along strike in that area. Although Moho reflections are not as well defined possibly due to lower fold, the combined section (Fig. 5) improves the lateral image of the Moho, documenting a continuous thinning seawards that reaches about $8 \mathrm{~km}$ in 20 $\mathrm{km}$ borizontal distance. The geometry of the Moho obtained in the stacked sections along profiles I and ESCI is consistent with the results of the velocity-depth forward modellings (see Fig. 3).

Non-volcanic Atlantic type margins like the Iberian Atlantic ones (Whitmarșh et al., 1993), the Newfounland basin (Reid, 1994) or the Carolina trough, U.S. East coast (Holbrook et al., 1992) are characterized by a thin crust with high lower crustal velocities underlied by an anomalous upper mantle. Underplating or altered upper mantle material like serpentinite or peridotite are common hypothesis of margin formation. Although having similarities with the initial rifting stages of the Atlantic margins formation, fundamental differences arise in the deep structure of the Catalan margin, not fully developed and with rather low velocities around $6.4-6.5 \mathrm{~km} / \mathrm{s}$ found in the lower crust (Dañobeitia et al., 1992; Gallart et al., 1994; Vidal et al., 1994). The present-day deep structure of the transition from the NE Iberian Peninsula to the Mediterranean Sea could be related to the succession in the area of compressional and extensional processes since Mesozoic times, some of them coeval, such as the Neogene block faulting at the Catalan margin and thrust/folding at the Betic-Balearic domain.

\section{Acknowledgments}

The ESCI seismic programme is supported by the Spanish "Plan Nacional de I+D". This work has been partially financed by CICYT projects $n^{\circ}$ GEO89-0858-E; GEO90-0733 and PB86-0619. N. Vidal benefited from a CICYT PhD-grant.

\section{References}

Banda, E. and P. Santanach, The Valencia trough (Western Mediterranean): an overview, Tectonophysics, 208, 183-202, 1992.

Collier, J.S., Buhl, P., Torné, M. and A.B. Watts, Moho and lower crustal reflectivity beneath a young rift basin: results from a two-ship, wide-aperture seismic reflection experiment in the Valencia trough (Western Mediterranean), Geophys. J. Int., 118, 1, 159-180, 1994.
Dañobeitia, J.J., Arguedas, M., Gallart, J., Banda, E. and J. Makris, Deep crustal configuration of the Valencia trough and its Iberian and Balearic borders from extensive refraction and wide-angle reflection profiling, Tectonophysics, 203, 37-55, 1992.

Gallart, J., Vidal, N., Dañobeitia, J.J., and the ESCI-Valencia Trough Working Group, Lateral variations in the deep crustal structure at the Iberian margin of the Valencia trough imaged from seismic reflection methods, Tectonophysics, 232, 59-75, 1994.

Holbrook, S.W., Reiter, E.C., Purdy, G.M. and M.N. Tocsöz, Image of the Moho across the continent-ocean transition, U.S. east coast, Geology, 20, 203-206, 1992.

Mooney, W.D. and T.M. Brocher, Coincident seismic reflection/refraction studies of the continental lithosphere: A global review, Rev. Geophys., 25, 723-742, 1987.

Pascal, G., Torné, M., Buhl, P. Watts, A.B. and A. Mauffret, Crustal and velocity structure of the Valencia trough (Western Mediterranean), Part II. Detailed interpretation of five Expanded Spread Profiles, Tectonophysics, 203, 21-35, 1992.

Reid, I., Crustal structure of a nonvolcanic rifted margin east of Newfoundland, J. Geophys. Res., in press, 1994.

Suriñach, E., Marthelot, J.M., Gallart, J., Daignières, M. and A. Him, Seismic images and evolution of the Iberian crust in the Pyrenees, Tectonophysics, 221, 67-80, 1993.

Torne, M., Pascal, G., Buhl, P., Watts, A.B. and A. Mauffret, Crustal and velocity structure of the Valencia trough (western Mediterranean), Part I. A combined refraction/wide angle reflection and near vertical reflection study, Tectonophysics, 203, 1-20, 1992.

Vidal, N., Gallart, J., Dañobeitia, J.J. and J. Díaz, Mapping the Moho at the Iberian Mediterranean margin by multicoverage processing and merging of wide-angle and near-vertical reflection data, in Rifted Ocean-Continent Boundaries, Kluwer-NATO Book, edited by E. Banda, M. Talwani and M. Torné, in press, 1994.

Whitmarsh, R.B., Pinheiro, L.M., Miles, P.R., Recq, M. and J.C. Sibuet, Thin crust at the western Iberia ocean-continent transition and ophiolites, Tectonics, 12, 1230-1239, 1993.

J. Gallart, N. Vidal and J.J. Dañobeitia, Institute of Earth Sciences "Jaume Almera"-CSIC, Martí i Franquès s/n, 08028 Barcelona, Spain.

Received September 8, 1994; revised September 12, 1994; accepted December 12, 1994) 